\title{
A Nonlinear Constitutive Model for Disintegrated Carbonaceous Mudstone Based on Logarithmic Functions
}

\author{
Xiang Qiu, ${ }^{1,2}$ Jinhong Li, ${ }^{1}$ Huangbin Jiang $\mathbb{D}^{3}{ }^{3}$ Hongyuan Fu, ${ }^{1}$ and Shun Yang ${ }^{1}$ \\ ${ }^{1}$ School of Civil Engineering, Changsha University of Science and Technology, Changsha 410114, Hunan, China \\ ${ }^{2}$ Key Laboratory of Road Structure and Materials Transportation Industry, Changsha 410114, China \\ ${ }^{3}$ School of Traffic and Transportation Engineering, Changsha University of Science and Technology, Changsha, Hunan \\ 410114, China \\ Correspondence should be addressed to Huangbin Jiang; jianghuangbin@stu.csust.edu.cn
}

Received 26 December 2020; Revised 4 April 2021; Accepted 12 April 2021; Published 23 April 2021

Academic Editor: Li Chen

Copyright (c) 2021 Xiang Qiu et al. This is an open access article distributed under the Creative Commons Attribution License, which permits unrestricted use, distribution, and reproduction in any medium, provided the original work is properly cited.

\begin{abstract}
To study the mechanical characteristics of the disintegrated carbonaceous mudstone (DCM), consolidated drained triaxial tests were conducted on the DCM with three degrees of compaction (i.e., 90\%, 93\%, and 96\%). Then, the nonlinear constitutive model suitable for the DCM was established based on test results using a logarithmic function. The stress-strain characteristics of the DCM were analyzed. The results revealed that the axial strain of the DCM was positively correlated with the deviatoric stress and lateral strain. The slopes of deviatoric stress-axial strain curves decreased with the increase of axial strain and so did the slopes of the axial strain-volumetric strain curves. The strength of the DCM increased with the increase of the confining pressure and the degree of compaction. In addition, the axial strain induced by dilatancy was also positively correlated with the degree of compaction and the confining pressure. Furthermore, under triaxial loading conditions, the relationship between the stress and strain of the DCM can be expressed by a logarithmic function; based on this, a nonlinear constitutive model with ten material parameters was derived. In addition, the results of numerical tests using the model showed similar stress-strain characteristics of the DCM comparing with the triaxial tests. Hence, it indicated that the nonlinear constitutive model based on the logarithmic function can reflect the nonlinear stress-strain characteristics of the DCM.
\end{abstract}

\section{Introduction}

In the southwestern of China, the disintegrated carbonaceous mudstone (DCM) was widely used as embankment fillers [1]. However, the DCM was characterized by complex component, low strength, and large compressibility. Although a significant amount of research has been performed to reveal the mechanical characteristics of the DCM, it is still difficult to assess the stability of embankments or slopes of carbonaceous mudstone, which are affected by many factors such as water and geological conditions [2]. Thus, it is critical to understand the mechanical response of the DCM with different stress environment, drainage condition, and degree of compaction.

In past decades, a great deal of effort has been carried out to establish the prediction model of rock and soil deformations based on the stress-strain relationship
[3-6]. However, the rock and soil are characterized by heterogeneity, structure, brokenness, and complex component, which have a significant effect on the stressstrain relationship [7-10]. Nonlinear and elastoplastic constitutive models are widely used in engineering. Compared with the nonlinear elastic model, the elastoplastic model is considered more reliable to reflect the essential characteristics of the rock and soil. Normally, it is difficult to utilize the elastoplastic model to analyze the engineering field due to the complicated parameters [11-16]. Furthermore, the mathematical expression of a nonlinear constitutive model is relatively simple, and the physical meaning of parameters is clear and easy to determine based on the conventional triaxial test. Thus, the nonlinear constitutive model has been widely used, such as the $\mathrm{D}-\mathrm{C}$ model [17], E-B model [18, 19], and K-G model [20], in which the D-C model (Duncan-Zhang nonlinear 
model) was derived based on Mohr-Coulomb strength criterion.

A large number of engineering practices have shown that the deformation of the rock and soil increases with the increase of intermediate principal stress and major principal stress in the embankment, Earth, and rockfill dam and other Earth filling projects $[12,21,22]$. However, the influence of intermediate principal stress changes on the shear behavior of rock and soil has been ignored in most nonlinear constitutive models, which may fail to meet the requirements of engineering. The mechanical properties of the rock and soil are complex, and a special rock and soil should have a suitable constitutive model to exhibit the stress-strain characteristics $[23,24]$. Therefore, it is a long-term goal for researchers to establish a simple and applicable constitutive model that can reflect the influence of stress changes on the behavior of rock and soil.

The focus of the current work is to analyze the mechanical characteristics of the DCM. The consolidated drained triaxial tests were carried out on DCM samples with different degrees of compaction. The characteristics of stress-strain, peak shear strength, and axial strain during the process of dilatancy were analyzed. A nonlinear constitutive model suitable for the DCM was derived using logarithmic functions based on test results. Then, the numerical simulations of DCM under different conditions of degrees of compaction and confining pressures were performed by using the new nonlinear constitutive model. The numerical simulation results were compared with those of triaxial tests to verify the applicability of the new nonlinear constitutive model.

\section{Triaxial Test of DCM}

2.1. Material Properties. Typical completely DCM was collected from the site of K18+500 of the Liuzhai-Hechi expressway in Guangxi, China. The main physical properties of the DCM are shown in Table 1. Figure 1 shows the grain size distribution. It can be observed that the grain sizes of the material less than $3.49 \mathrm{~mm}, 2.18 \mathrm{~mm}$, and $0.62 \mathrm{~mm}$ are $60 \%$, $30 \%$, and $10 \%$, respectively. The calculated coefficient of uniformity and coefficient of curvature are 5.63 and 2.17, respectively. This indicates that the material had a satisfactory grain composition according to the Chinese national standard GB/T 50123.

2.2. Sample Preparation and Test Procedure. The preparation method of DCM sample is as follows: the static pressure method was used for layered compaction; after compaction and static $120 \mathrm{~s}$, the layer surface was scraped, and then, the next layer was compacted. Finally, DCM samples with three degrees of compaction $(90 \%, 93 \%$, and $96 \%$ ) were prepared (a diameter of $100 \mathrm{~mm}$ and a height of $200 \mathrm{~mm}$ ). As shown in Figure 2, consolidated drained triaxial tests were conducted using a triaxial compression servo testing machine developed by the Institute of Rock and Soil Mechanics, Chinese Academy of Sciences. The specific steps of triaxial tests were as follows. First, the DCM sample enveloped with a membrane was placed in a sealed cylinder filled with water, and the air in the sealed cylinder was discharged to make the sample saturated. Second, the saturated sample was transferred in the triaxial loading chamber, and the tubes of the test device were connected. Then, the sample was consolidated under different confining pressures, i.e., $50 \mathrm{kPa}$, $100 \mathrm{kPa}$, and $150 \mathrm{kPa}$. According to the Chinese Standard JTG E40-2007, when the volume change of the sample was less than $5 \mathrm{~mm}^{3}$ within $5 \mathrm{~min}$, the consolidation of the sample was considered complete. Finally, triaxial shearing was performed at a shear rate of $0.01 \mathrm{~mm} / \mathrm{min}$ using the strain-controlled method until the axial strain reached $20 \%$.

\section{Test Results}

Figures (3a-3c) show that the typical curves between deviatoric stress and axial strain of DCM samples with degrees of compaction of $90 \%, 93 \%$, and $96 \%$, respectively. It can be observed that, under different degree of compaction and confining pressure conditions, the deviatoric stress is positively correlated with the axial strain, and it has a failure characteristic of strain harden. According to the slope of the relationship curve between deviatoric stress and axial strain, the changing process of the deviatoric stress of the sample with the increase of axial strain is divided into three stages: linear rapid increase, nonlinear continuous increase, and linear slow increase. The relationship between the deviatoric stress and the axial strain of the samples are quantified by a series of logarithmic functions, whose general expression is as follows:

$$
y=a \ln (b x+1),
$$

where $a$ and $b$ are fitting parameters.

The values of fitting parameters under different degrees of compaction and confining pressures are shown in Figure 3. The $a$ value is positively correlated with the degree of compaction and confining pressure, and the $b$ value is negatively correlated with the degree of compaction and confining pressure.

Since the deviatoric stress-axial strain curves have no peaks, the deviatoric stress corresponding to an axial strain of $15 \%$ is taken as the peak shear strength according to the Chinese Standard JTG 3430-2020. As an example, the deviatoric stress-axial strain curve of the sample having a degree of compaction of $90 \%$ is shown in Figure 3(a). When the confining pressures are $50 \mathrm{kPa}, 100 \mathrm{kPa}$, and $150 \mathrm{kPa}$, the peak strengths are $62.93 \mathrm{kPa}, 98.85 \mathrm{kPa}$, and $146.89 \mathrm{kPa}$, respectively. In addition, when the degree of compaction is $93 \%$, the peak strengths corresponding to the three different confining pressures are $86.14 \mathrm{kPa}, 131.51 \mathrm{kPa}$, and $195.78 \mathrm{kPa}$, respectively; while the degree of compaction is $96 \%$, the peak strengths of the samples at different confining pressures are $115.67 \mathrm{kPa}, 162.63 \mathrm{kPa}$, and $243.72 \mathrm{kPa}$, respectively. It can be seen that the peak strength of the sample is positively correlated with the degree of compaction and confining pressure.

The comparative image of a representative sample before and after the test is shown in Figure 4. The DCM sample did 
TABLE 1: Main physical properties of DCM.

\begin{tabular}{lcccc}
\hline Maximum dry density $\left(\mathrm{g} \cdot \mathrm{cm}^{-3}\right)$ & Optimum moisture content (\%) & Natural moisture content (\%) & Plastic limit (\%) & Liquid limit (\%) \\
\hline 1.86 & 13.82 & 8.79 & 22.42 & 35.21
\end{tabular}

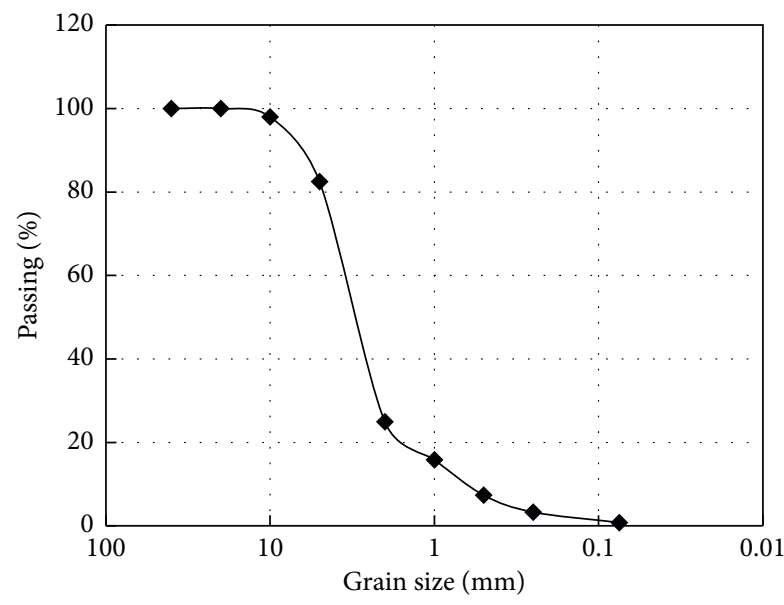

Figure 1: Grain size distribution of the DCM.

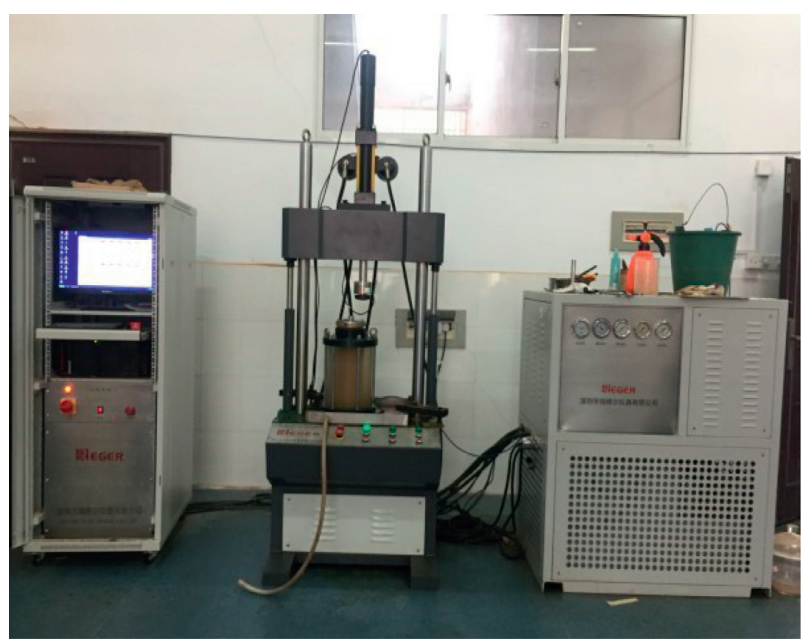

Figure 2: Triaxial compression servo testing machine.

not undergo shear failure before the axial strain reached $20 \%$, but a lateral deformation bulge occurred near one-third of the sample height from the bottom of the sample.

Figures $(5 a-5 c)$ show that the axial strain-lateral strain curves of DCM samples with degrees of compaction of $90 \%$, $93 \%$, and $96 \%$, respectively. The lateral strain is positively correlated with the axial strain under different degrees of compaction and confining pressure conditions, and the slope of the curve decreases with the increase of the lateral strain. Similarly, equation (1) can be used to quantify the relationship between the axial strain and lateral strain. However, in this case, $a$ and $b$ are positively correlated with the degree of compaction, and both $a$ and $b$ do not change much under the same confining pressure condition.

In triaxial tests, the dilatancy angle can usually be calculated by the following equation:

$$
\tan \psi=-\frac{\left(d \varepsilon_{1}+2 d \varepsilon_{3}\right)}{\left(d \varepsilon_{1}-d \varepsilon_{3}\right)},
$$

where $\psi$ is the dilatancy angle, $\varepsilon_{1}$ is the axial strain, and $\varepsilon_{3}$ is the lateral strain.

If the slope of the axial strain-lateral strain curve is more than 2, then $\mathrm{d} \varepsilon_{1}$ is less than $\mathrm{d} \varepsilon_{3}$, and $\tan \psi$ is a positive number. Thus, the sample undergoes dilatancy. On the contrary, the sample undergoes shear contraction.

The slope of the axial strain-lateral strain curve is negatively correlated with the lateral strain, which can be expressed by

$$
y=\frac{a b}{b x+1}
$$

where $a$ and $b$ are fitting parameters.

The axial strain induced by shear stress (i.e., shear shrinking transformation into dilatancy) is referred to as $\varepsilon_{s}$. To conveniently calculate $\varepsilon_{\mathrm{s}}$, the slope of the axial strainlateral strain curve is assumed to be 2 . After calculation, at a degree of compaction of $90 \%, \varepsilon_{s}$ is $0.0152,0.0202$, and 0.0232 under confining pressures of $50 \mathrm{kPa}, 100 \mathrm{kPa}$, and $150 \mathrm{kPa}$, respectively. At a degree of compaction of $93 \%, \mathcal{E}_{\mathrm{s}}$ is 0.0228 , 0.0298 , and 0.0456 under confining pressures of $50 \mathrm{kPa}$, $100 \mathrm{kPa}$, and $150 \mathrm{kPa}$, respectively. At a degree of compaction is $96 \%, \varepsilon_{\mathrm{s}}$ is $0.0304,0.0396$, and 0.0437 under confining pressures of $50 \mathrm{kPa}, 100 \mathrm{kPa}$, and $150 \mathrm{kPa}$, respectively. It can be seen that $\varepsilon_{\mathrm{s}}$ has positively relationship with the degree of compaction and the confining pressure.

\section{New Nonlinear Constitutive Model and Its Verification}

\subsection{Derivation of Nonlinear Constitutive Model Based on Logarithmic Functions}

4.1.1. Applicable Conditions. The relationships between the deviatoric stress and axial strain and the axial strain and lateral strain of the sample can be obtained from Section 3. This stipulates the applicable conditions of the nonlinear constitutive model based on the logarithmic functions: (i) the deviatoric stress is positively correlated with the axial strain, and the axial strain is positively correlated with lateral strain; (ii) when the axial strain is less than 0.2, the deviatoric stress-axial strain curve and the axial strain-lateral strain curve have no peak.

4.1.2. Tangent Deformation Modulus $E_{t}$. It can be seen from Figure 3 that the relationship between the deviatoric stress $\left(\sigma_{1}-\sigma_{3}\right)$ and the axial strain $\varepsilon_{1}$ of the sample satisfies

$$
\left(\sigma_{1}-\sigma_{3}\right)=a \ln \left(b \varepsilon_{1}+1\right) \text {, }
$$




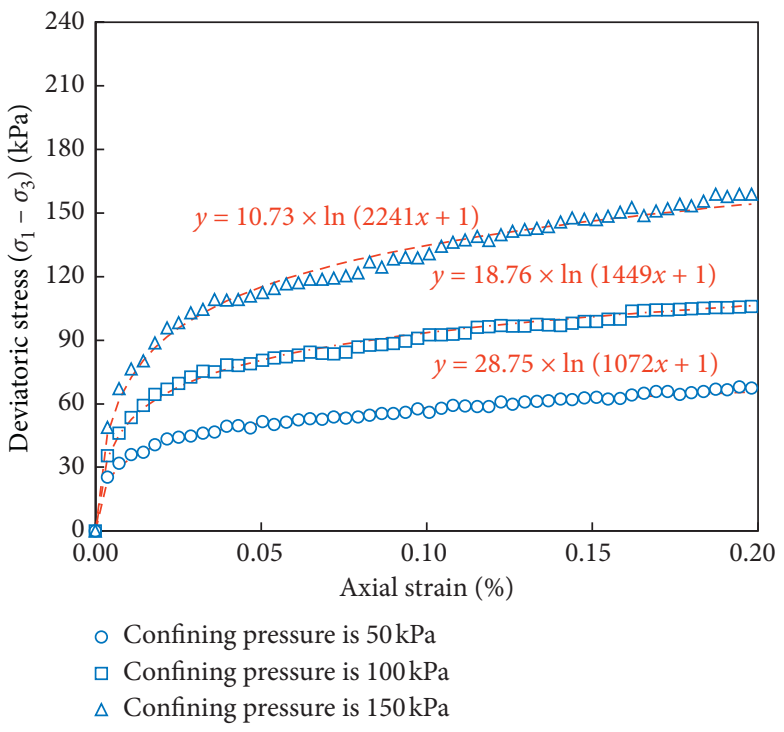

(a)

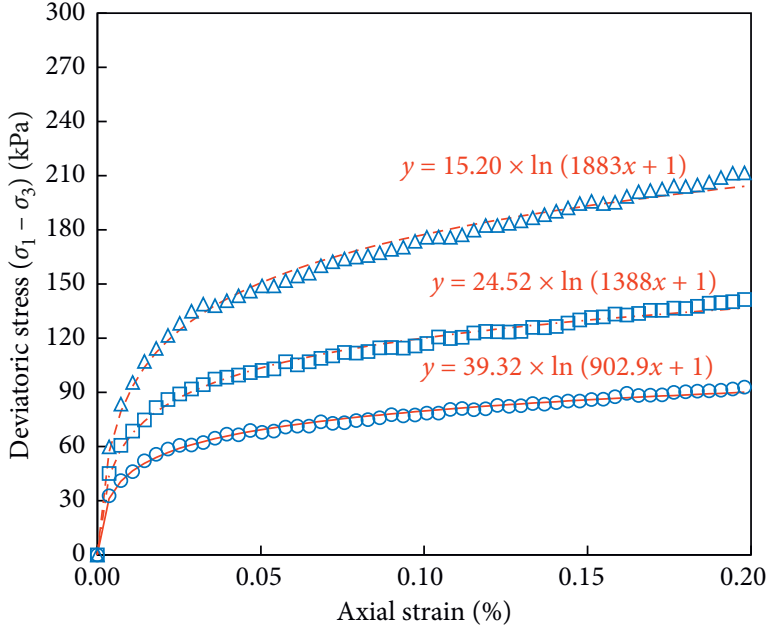

- Confining pressure is $50 \mathrm{kPa}$

$\square$ Confining pressure is $100 \mathrm{kPa}$

$\triangle$ Confining pressure is $150 \mathrm{kPa}$

(b)

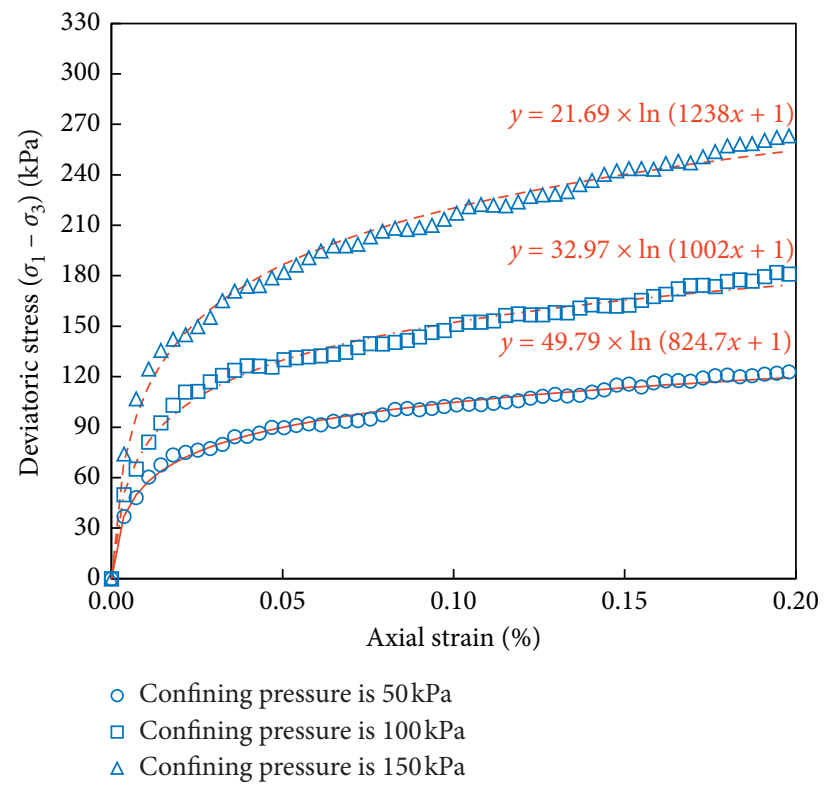

(c)

Figure 3: Relationship between deviatoric stress and axial strain: (a) degree of compaction is 90\%; (b) degree of compaction is 93\%; (c) degree of compaction is $96 \%$.

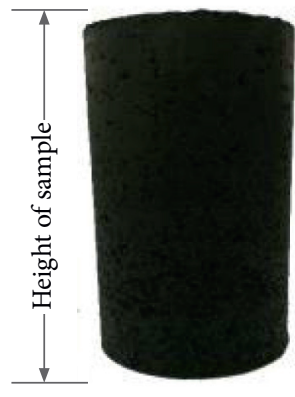

Before the test
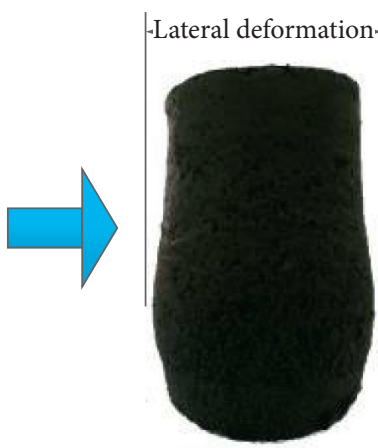

After the test

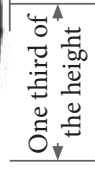

Or

Figure 4: Comparative image of a sample before and after the test.

where $\sigma_{1}$ is axial stress, $\sigma_{3}$ is confining pressure, and $a$ and $b$ are fitting parameters $(a, b>0)$.

To obtain the tangent deformation modulus $E_{t}$ based on the relationship between the deviatoric stress and axial strain, equation (4) is rewritten as

$$
E_{t}=\frac{d\left(\sigma_{1}-\sigma_{3}\right)}{d \varepsilon_{1}}=\frac{a b}{b \varepsilon_{1}+1} .
$$

When the sample does not undergo axial strain $\left(\varepsilon_{1}=0\right)$, the tangent deformation modulus $E_{0, i}$ can be expressed by

$$
E_{0, i}=a b .
$$




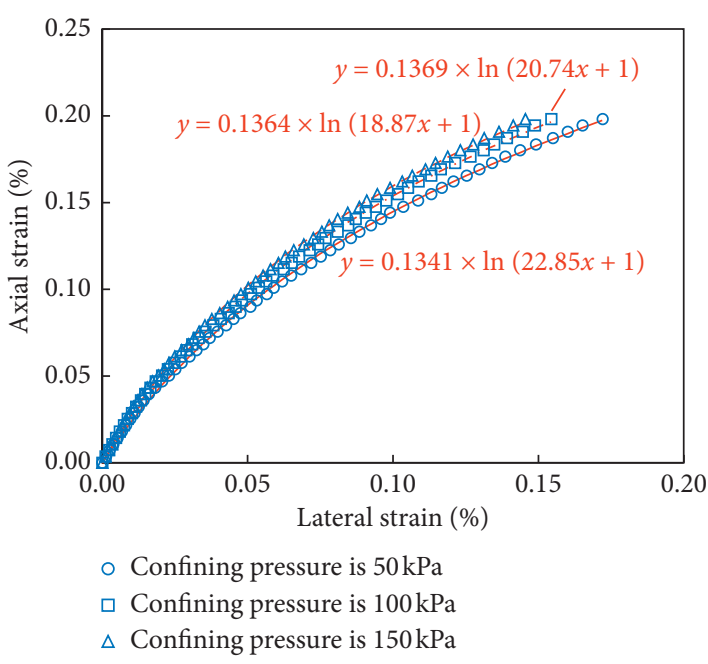

(a)

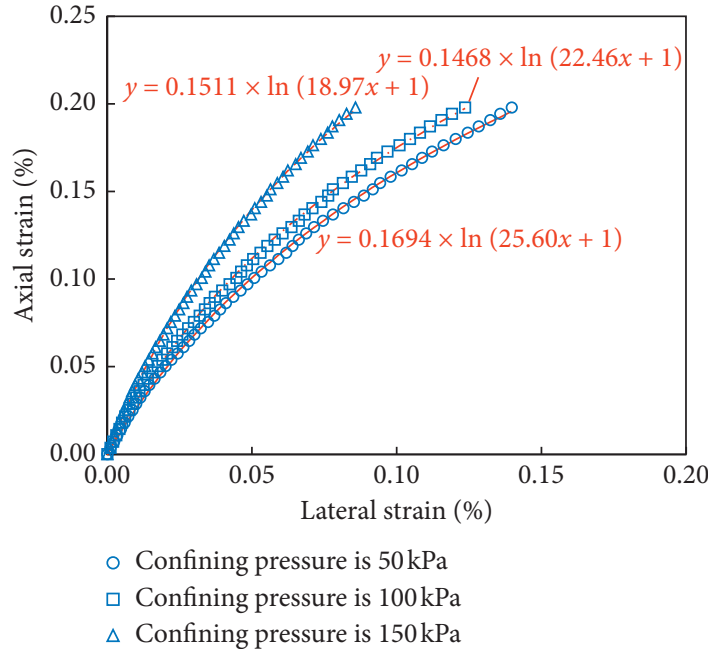

(b)

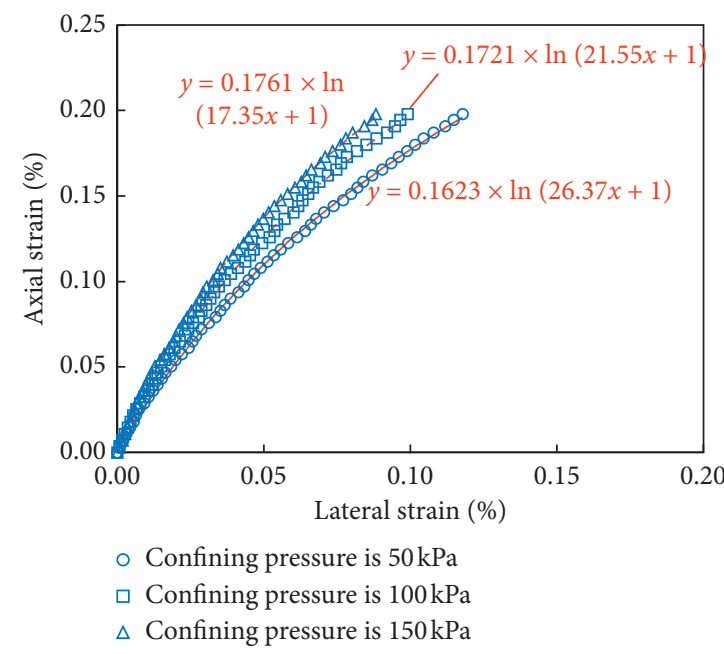

(c)

FIGURE 5: Relationship between axial strain and lateral strain: (a) degree of compaction is $90 \%$; (b) degree of compaction is $93 \%$; (c) degree of compaction is $96 \%$.

Substituting equation (6) into equation (5) yields

$$
\frac{1}{E_{t}}=\frac{1}{E_{0, i}}+\frac{\varepsilon_{1}}{a}
$$

According to the triaxial test results, when the axial strain is less than 0.2 , the deviatoric stress is positively correlated with the axial strain $\varepsilon_{1}$, and the deviatoric stressaxial strain curves have no peak. Therefore, the deviatoric stress corresponding to an axial strain of 0.2 is defined as the ultimate deviatoric stress $\left(\sigma_{1}-\sigma_{3}\right)_{u l t}$, which can be expressed by the following equation:

$$
\left(\sigma_{1}-\sigma_{3}\right)_{u l t}=a \ln (0.2 b+1)
$$

Furthermore, $\left(\sigma_{1}-\sigma_{3}\right)_{f}$ represents the peak deviatoric stress. Then, the expression of the failure stress ratio $R_{f}$ of the sample is

$$
R_{f}=\frac{\left(\sigma_{1}-\sigma_{3}\right)_{f}}{\left(\sigma_{1}-\sigma_{3}\right)_{u l t}}
$$

The following equation is derived by substituting equation (8) into equation (9):

$$
a=\frac{\left(\sigma_{1}-\sigma_{3}\right)_{f}}{R_{f} \ln (0.2 b+1)} .
$$

Substituting equation (10) into equation (7), one can derive 


$$
\frac{1}{E_{t}}=\frac{1}{E_{0, i}}+\frac{R_{f} \ln (0.2 b+1)}{\left(\sigma_{1}-\sigma_{3}\right)_{f}} \varepsilon_{1}
$$

where $E_{t}$ is a function related to the axial strain, which is converted into a function related to the deviatoric stress for the convenience of application. The methods are as follows.

Substituting equation (6) into equation (4) yields

$$
\varepsilon_{1}=\frac{\left(\exp \left(b\left(\sigma_{1}-\sigma_{3}\right) / E_{0, i}\right)-1\right)}{b} \text {. }
$$

Then, substituting equation (12) into equation (11), further yields the following equation:

$$
\frac{1}{E_{t}}=\frac{1}{E_{0, i}}+\frac{R_{f} \ln (0.2 b+1)}{\left(\sigma_{1}-\sigma_{3}\right)_{f}} \frac{\left(\exp \left(b\left(\sigma_{1}-\sigma_{3}\right) / E_{0, i}\right)-1\right)}{b} \text {. }
$$

According to the Mohr-Coulomb strength criterion, the calculation formula of the peak deviatoric stress is

$$
\left(\sigma_{1}-\sigma_{3}\right)_{f}=\frac{2 c \cos \varphi+2 \sigma_{3} \sin \varphi}{1-\sin \varphi}
$$

$$
\begin{aligned}
\frac{1}{E_{t}}= & \frac{1}{K p_{a}\left(\sigma_{3} / p_{a}\right)^{n}} \\
& +\frac{R_{f} \ln \left(0.2\left(X \sigma_{3}+J\right)+1\right)(1-\sin \varphi)}{2 c \cos \varphi+2 \sigma_{3} \sin \varphi} \frac{\left(\exp \left(\left(X \sigma_{3}+J\right)\left(\sigma_{1}-\sigma_{3}\right) / K p_{a}\left(\sigma_{3} / p_{a}\right)^{n}\right)-1\right)}{\left(X \sigma_{3}+J\right)} .
\end{aligned}
$$

$$
v_{0, i}=\frac{1}{a^{\prime} b^{\prime}} .
$$

It can be seen that the expression of tangential deformation modulus contains seven parameters $(K, n, c, \varphi$, $\left.R_{f}, X, J\right)$.

4.1.3. Tangent Poisson Ratio $v_{t}$. Similarly, the relationship between the axial strain $\left(\varepsilon_{1}\right)$ and lateral strain $\left(\varepsilon_{3}\right)$ can be expressed by

$$
\varepsilon_{1}=a^{\prime} \ln \left(b^{\prime}\left(-\varepsilon_{3}\right)+1\right),
$$

where $a^{\prime}$ and $b^{\prime}$ are fitting parameters $\left(a^{\prime}, b^{\prime}>0\right)$.

The tangent Poisson ratio $v_{\mathrm{t}}$ can be derived from equation (18):

$$
v_{t}=\frac{d\left(-\varepsilon_{3}\right)}{d \varepsilon_{1}}=\frac{1}{a^{\prime} b^{\prime}} \exp \left(\frac{\varepsilon_{1}}{a^{\prime}}\right) .
$$

When the sample does not undergo axial strain $\left(\varepsilon_{1}=0\right)$, the tangent Poisson ratio $v_{0, i}$ can be calculated by where $c$ is the cohesion and $\varphi$ is internal friction angle. The cohesions and internal friction angles of samples with different degrees of compaction can be obtained according to the strength envelope shown in Figure 6 (i e., $c$ is equal to the intercept of the strength envelope and $\varphi$ is equal to the slope of the intensity envelope).

Figure 7 shows the relationship between the parameter $b$ and the confining pressure $\sigma_{3}$, and Figure 8 presents the relationship between $\lg \left(E_{0, I} / p_{a}\right)$ and $\lg \left(\sigma_{3} / p_{a}\right)$. Their expressions are equations (15) and (16), respectively:

$$
\begin{aligned}
b & =X \sigma_{3}+J, \\
E_{0, i} & =K p_{a}\left(\sigma_{3} / p_{a}\right)^{n},
\end{aligned}
$$

where $X, J, K$, and $n$ are fitting parameters and $p_{a}$ is a standard atmospheric pressure $\left(p_{a}=101.4 \mathrm{kPa}\right)$.

Finally, equations (14)-(16) are substituted into equation (13), and thus, the following equation is derived:
Substituting equation (20) into equation (19), one can derive the following equations:

$$
\begin{aligned}
& a^{\prime}=\frac{\varepsilon_{1}}{\ln \left(v_{t} / v_{0, i}\right)}, \\
& v_{t}=v_{0, i} \exp \left(\frac{\varepsilon_{1}}{a^{\prime}}\right) .
\end{aligned}
$$

Figure 9 shows the relationship between $v_{0, i}$ and $\lg \left(\sigma_{3} / p_{a}\right)$, which can be characterized by

$$
v_{0, i}=G-F \lg \left(\sigma_{3} / p_{a}\right)
$$

where $G$ and $F$ are fitting parameters.

Substituting equations (6), (10), (12), and (23) into equation (22), one can obtain

$$
\begin{aligned}
v_{t}= & \left(G-F \lg \left(\sigma_{3} / p_{a}\right)\right) \\
& \times \exp \left(\frac{\left(2 c \cos \varphi+2 \sigma_{3} \sin \varphi\right)\left(\exp \left(\left(\sigma_{1}-\sigma_{3}\right) R_{f} \ln \left(0.2\left(X \sigma_{3}+J\right)+1\right)(1-\sin \varphi) / 2 c \cos \varphi+2 \sigma_{3} \sin \varphi\right)-1\right)}{a^{\prime} K p_{a}\left(\sigma_{3} / p_{a}\right)^{n} R_{f} \ln \left(0.2\left(X \sigma_{3}+J\right)+1\right)(1-\sin \varphi)}\right) .
\end{aligned}
$$




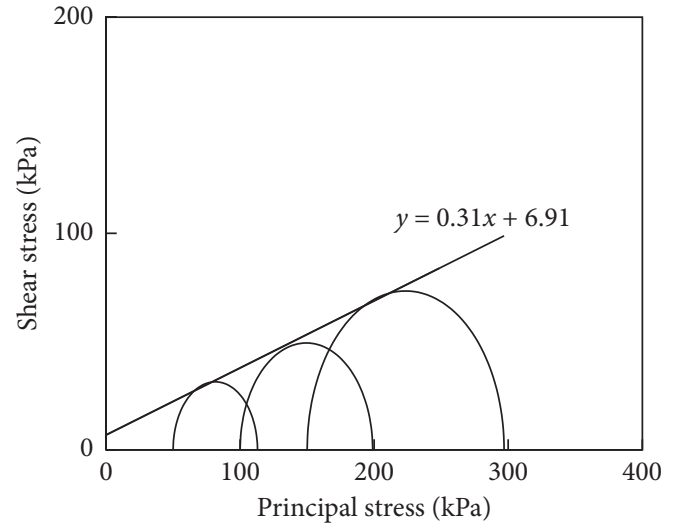

(a)

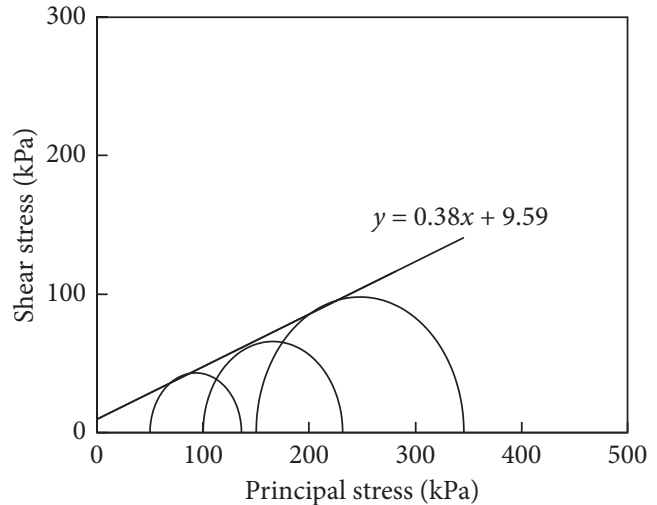

(b)

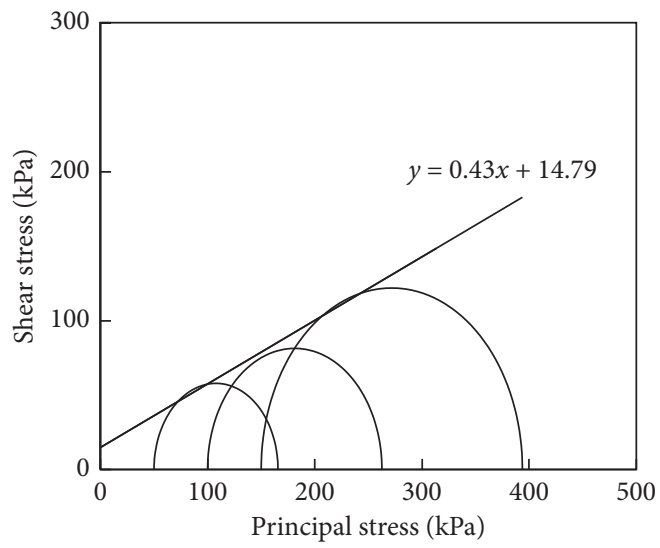

(c)

FIGURE 6: Strength envelope of samples with different degrees of compaction: (a) degree of compaction is 90\%; (b) degree of compaction is $93 \%$; (c) degree of compaction is $96 \%$.

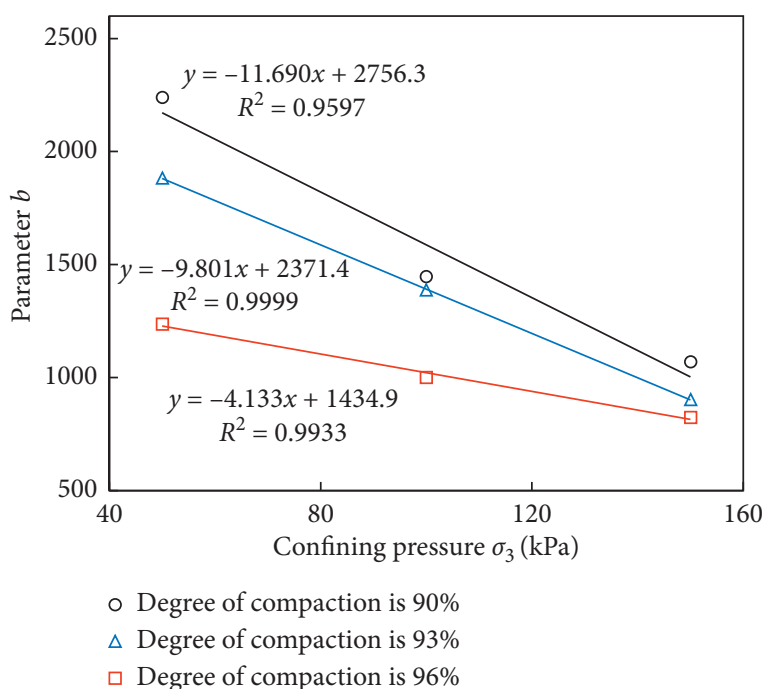

FIGURE 7: Relationship between the parameter $b$ and the confining pressure $\sigma_{3}$.

It can be seen that the expression of tangent Poisson ratio contains ten parameters $\left(K, n, c, \varphi, R_{f}, X, J, G, F, a^{\prime}\right)$. According to the theory of elasticity, the range of $v_{t}$ is $0-0.49$.
If the calculated $\nu_{\mathrm{t}}$ is greater than or equal to 0.49 , the value of $v_{\mathrm{t}}$ is considered to be 0.49 .

\subsection{Verification of the Nonlinear Constitutive Model Based on} Logarithmic Functions. Based on the results in Figures 3-9, the parameters of the nonlinear constitutive model for the DCM of different degrees of compaction are calculated by the equations in Sections 3 and 4, as shown in Table 2.

The strain increment was divided into a series of substep strain increments by the improved Euler integral algorithm, and the UMAT subroutine of the proposed nonlinear constitutive model was written in Fortran language. Based on the ABAQUS finite element software platform incorporated with the nonlinear constitutive model, the triaxial tests of the DCM under different degrees of compaction and confining pressures were simulated. The finite element calculation model is shown in Figure 10. The model has a diameter of $100 \mathrm{~mm}$ and a height of $200 \mathrm{~mm}$. According to the triaxial test procedure, the corresponding confining pressure was applied first and then the axial stress was applied to the top of the model, and the order of application of the deviatoric stress was consistent with the order of the deviatoric stress acquired during the triaxial test. 


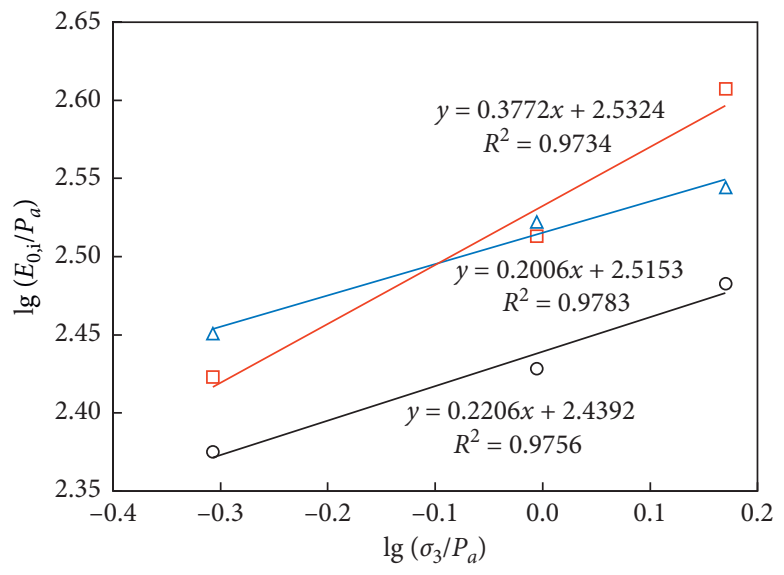

$\circ$ Degree of compaction is $90 \%$
$\triangle$ Degree of compaction is $93 \%$
$\square$ Degree of compaction is $96 \%$

Figure 8: Relationship between $\lg \left(E_{0, i} / \mathrm{pa}\right)$ and $\lg (\sigma 3 / \mathrm{pa})$.

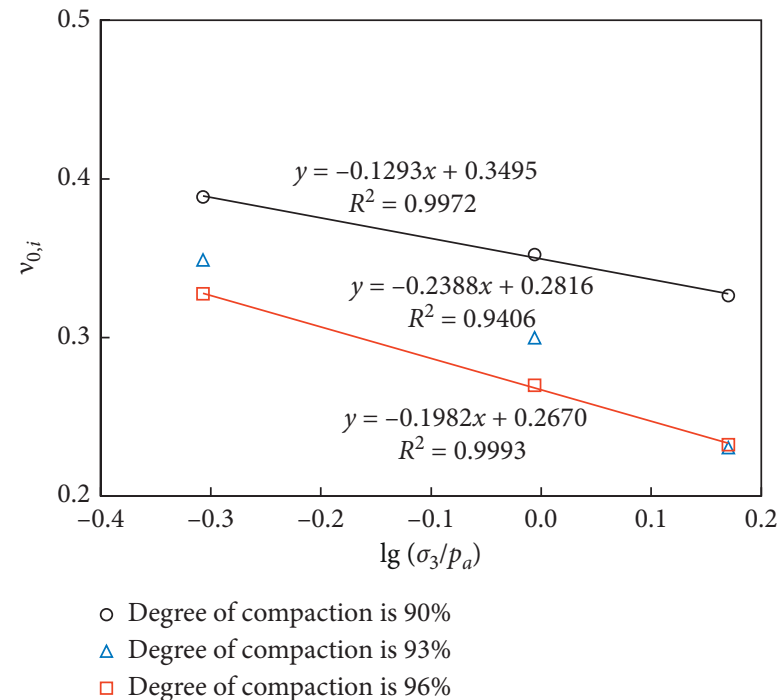

FIGURE 9: Relationship between $\nu_{0, i}$ and $\lg \left(\sigma_{3} / p_{a}\right)$.

TABLE 2: Nonlinear constitutive model parameters based on logarithmic functions.

\begin{tabular}{lccccccccccc}
\hline Degree of compaction (\%) & $K$ & $n$ & $c$ & $\varphi$ & $R_{f}$ & $X$ & $J$ & $G$ & $F$ \\
\hline 90 & 274.92 & 0.2206 & 6.91 & 17.22 & 0.9299 & -11.69 & 2756.3 & 0.3495 & 0.1293 & 0.1358 \\
93 & 327.57 & 0.2006 & 9.59 & 20.79 & 0.9273 & -9.80 & 2371.4 & 0.2816 & 0.2388 & 0.1564 \\
96 & 340.72 & 0.3772 & 14.79 & 23.11 & 0.9206 & -4.13 & 1434.9 & 0.2670 & 0.1982 & 0.1705 \\
\hline
\end{tabular}

The numerical calculation results (NCR) are compared with the triaxial test results (TTR) and are shown in Figure 11. It can be seen that, under different degrees of compaction and confining pressures, the new nonlinear constitutive model can well reflect the change trend of stress and strain of the DCM. To further reflect the accuracy of the new model, the relative error between the numerical calculation results and the triaxial test results was calculated, as illustrated in Figure 12. It shows that the relative error range of the deviatoric stress-axial strain curve is $\pm 25 \%$, and the relative error range of the deviatoric stress-lateral strain curve is $\pm 50 \%$ under different compaction and confining pressure conditions. At the same time, the shape of the deviatoric stress-strain curve fluctuates greatly, which is mainly caused by the re-disintegration of the coarse-grained carbonaceous mudstone during the test. In addition, the absolute values of the average relative errors of axial strain and lateral strain were also calculated, as listed in Tables 3 and 4. It shows that the absolute value of the relative error of axial strain $(10.69 \%)$ is significantly smaller than that of 


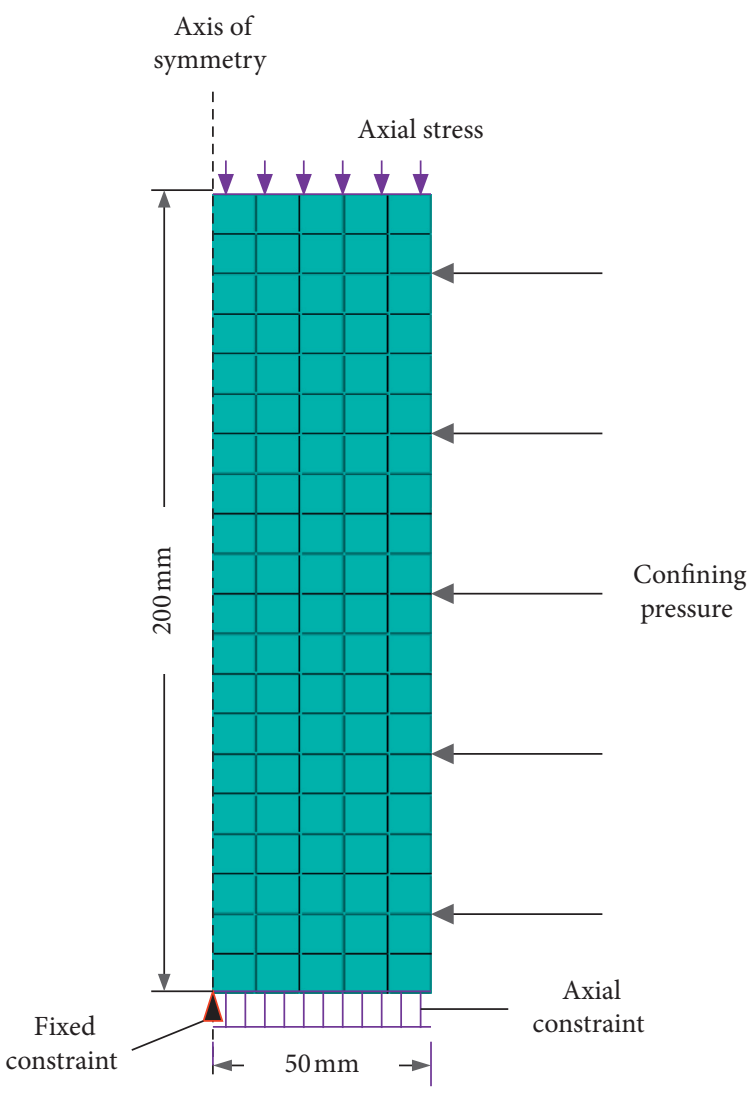

FIgURE 10: Finite element calculation model.

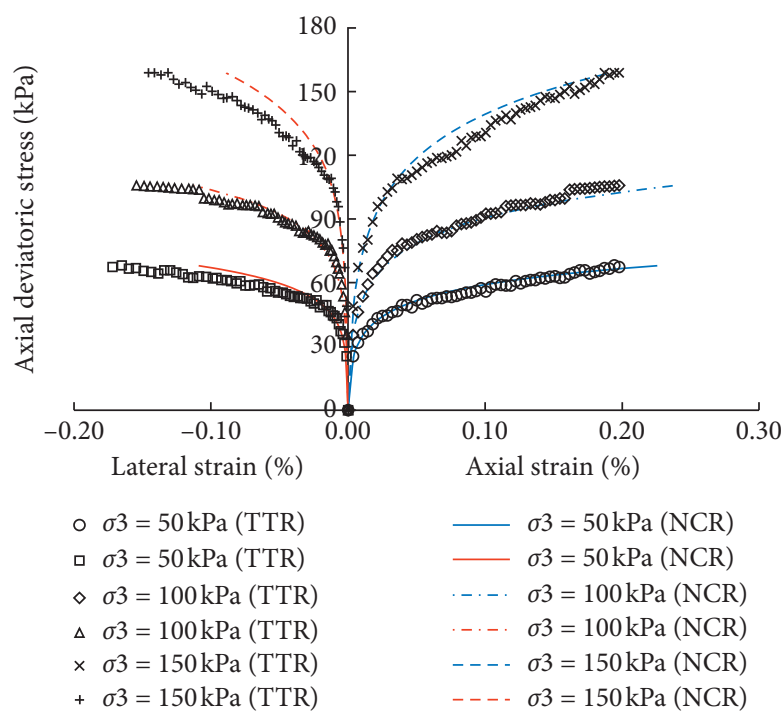

(a)

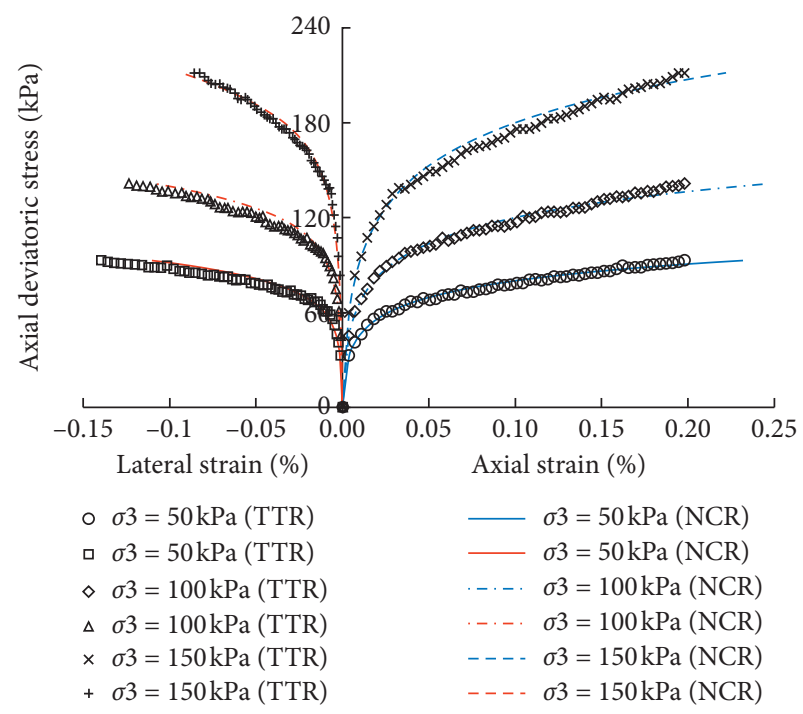

(b)

Figure 11: Continued. 


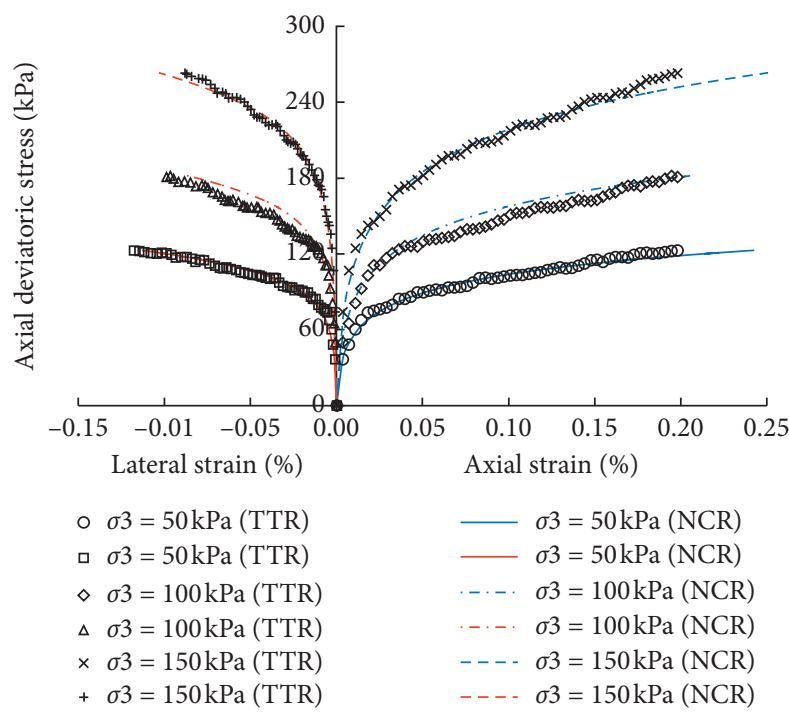

(c)

Figure 11: Comparison between numerical calculation results and triaxial test results: (a) degree of compaction is $90 \%$; (b) degree of compaction is $93 \%$; (c) degree of compaction is $96 \%$.

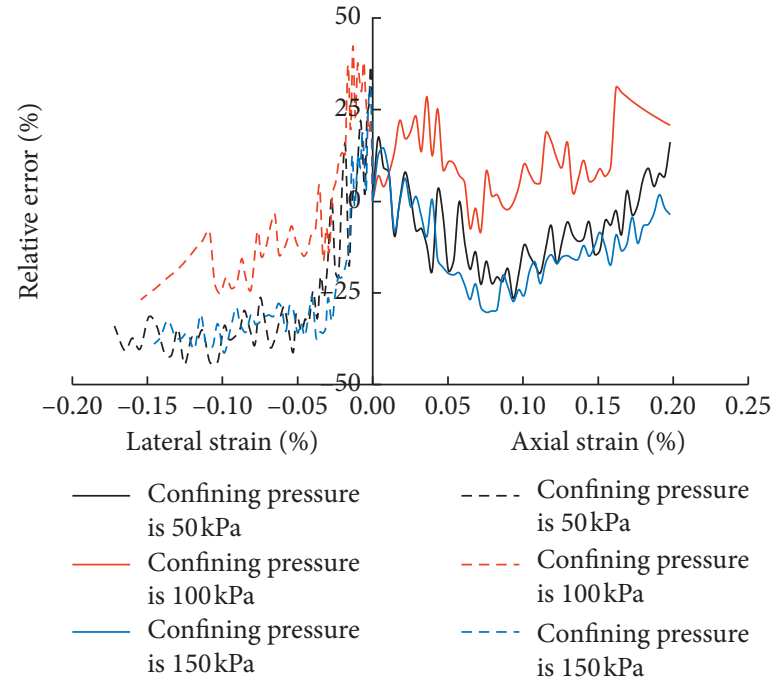

(a)

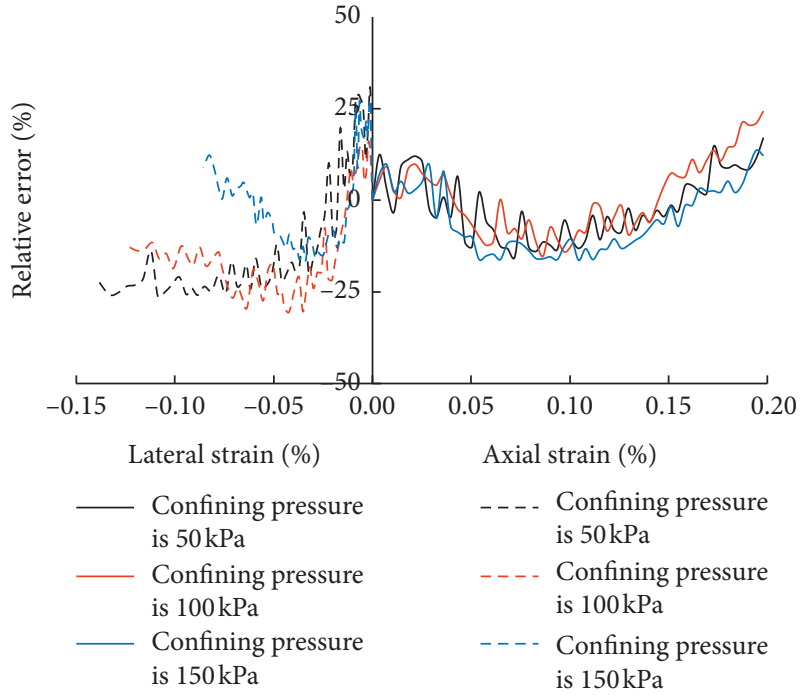

(b)

Figure 12: Continued. 


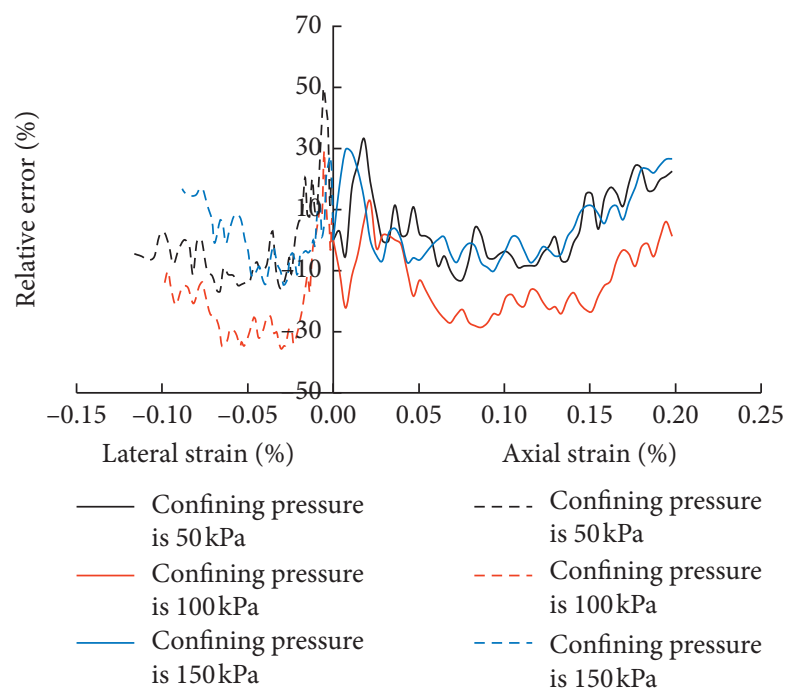

(c)

Figure 12: Relative error between the numerical calculation results and the triaxial test results: (a) degree of compaction is $90 \%$; (b) degree of compaction is $93 \%$; (c) degree of compaction is $96 \%$.

TABLE 3: Absolute value of relative error of axial strain (\%).

\begin{tabular}{lccc}
\hline \multirow{2}{*}{ Degree of compaction } & \multicolumn{3}{c}{ Confining pressure } \\
& $50 \mathrm{kPa}$ & $100 \mathrm{kPa}$ & $150 \mathrm{kPa}$ \\
\hline $90 \%$ & 10.97 & 12.65 & 14.1 \\
$93 \%$ & 7.81 & 8.33 & 9.06 \\
$96 \%$ & 9.65 & 14.76 & 8.91 \\
Average value & & 10.69 & \\
\hline
\end{tabular}

TABLE 4: Absolute value of relative error of lateral strain (\%).

\begin{tabular}{lccc}
\hline \multirow{2}{*}{ Degree of compaction } & \multicolumn{3}{c}{ Confining pressure } \\
& $50 \mathrm{kPa}$ & $100 \mathrm{kPa}$ & $150 \mathrm{kPa}$ \\
\hline $90 \%$ & 28.04 & 17.35 & 27.79 \\
$93 \%$ & 18.81 & 16.96 & 10.43 \\
$96 \%$ & 11.47 & 21.78 & 9.19 \\
Average value & & 17.98 & \\
\hline
\end{tabular}

lateral strain (17.98\%). Therefore, when the nonlinear constitutive model is used to predict the stress-strain relationship of the DCM, the prediction accuracy of the deviatoric stress-axial strain curve is better than that of the deviatoric stress-lateral strain curve.

\section{Conclusions}

In this paper, triaxial test results of the DCM under different degrees of compaction and confining pressures were presented. A nonlinear constitutive model based on logarithmic functions for the DCM was derived, and the accuracy of the nonlinear constitutive model was analyzed. The following conclusions are summarized:

(1) Under triaxial loading conditions, both the deviatoric stress and lateral strain of the DCM is positively correlated with the axial strain. The peak shear strength of the DCM is positively correlated with the degree of compaction and the confining pressure. In addition, the axial strain induced by dilatancy is also positively correlated with the degree of compaction and the confining pressure.

(2) The DCM sample did not undergo shear failure before the axial strain reached $20 \%$, but a lateral deformation bulge occurred near one-third of the sample height from the bottom of the sample.

(3) The relationship between the deviatoric stress and the axial strain and the relationship between the axial strain and the lateral strain of the DCM can be well quantified by a nonlinear constitutive model including ten material parameters based on logarithmic function. However, the new model has a better prediction accuracy for the deviatoric stressaxial strain curve than for the deviatoric stress-lateral strain curve.

\section{Data Availability}

The data used to support the findings of this study are available from the corresponding author upon request.

\section{Conflicts of Interest}

The authors declare that they have no conflicts of interest.

\section{Acknowledgments}

This paper was funded by Projects (51838001 and 51908073) supported by the National Natural Science Foundation of China, Project (2019SK2171) supported by the Key Research and Development Program of Hunan Province, China, and Project (2020JJ5581) supported by the Natural Science Foundation of Hunan Province. 


\section{References}

[1] L. Zeng, "Evolution characteristics of the cracks in the completely disintegrated carbonaceous mudstone subjected to cyclic wetting and drying," Advances in Civil Engineering, vol. 2019, Article ID 1279695, 9 pages, 2019.

[2] J. Zhang, F. Gu, and Y. Zhang, "Use of building-related construction and demolition wastes in highway embankment: laboratory and field evaluations," Journal of Cleaner Production, vol. 230, pp. 1051-1060, 2019.

[3] K.-E. Kurrer, "The history of the theory of structures: from arch analysis to computational mechanics," International Journal of Space Structures, vol. 23, no. 3, pp. 193-197, 2008.

[4] B. Zhang and K. K. Muraleetharan, "Implementation of a hydromechanical elastoplastic constitutive model for fully coupled dynamic analysis of unsaturated soils and its validation using centrifuge test results," Acta Geotechnica, vol. 14, no. 2, pp. 347-360, 2019.

[5] Q.-F. Gao, H. Dong, R. Huang, and Z.-F. Li, "Structural characteristics and hydraulic conductivity of an eluvialcolluvial gravelly soil," Bulletin of Engineering Geology and the Environment, vol. 78, no. 7, pp. 5011-5028, 2019.

[6] Z. Huang, Y. Chen, and S.-L. Bai, "An elastoplastic constitutive model for porous materials," International Journal of Applied Mechanics, vol. 05, no. 03, p. 1350035, 2013.

[7] J. Zhang and M. Luo, "Dilatancy and critical state of calcareous sand incorporating particle breakage," International Journal of Geomechanics, vol. 20, no. 4, Article ID 04020030, 2020.

[8] Y. Xiao, Z. Sun, A. W. Stuedlein, C. Wang, Z. Wu, and Z. Zhang, "Bounding surface plasticity model for stress-strain and grain-crushing behaviors of rockfill materials," Geoscience Frontiers, vol. 11, no. 2, pp. 495-510, 2020.

[9] Y. Xiao and H. Liu, "Elastoplastic constitutive model for rockfill materials considering particle breakage," International Journal of Geomechanics, vol. 17, no. 1, Article ID 04016041, 2017.

[10] Y. Xiao, H. Liu, X. Ding, Y. Chen, J. Jiang, and W. Zhang, "Influence of particle breakage on critical state line of rockfill material," International Journal of Geomechanics, vol. 16, no. 1, Article ID 04015031, 2016.

[11] G.-H. Yang, J. Yu-xin, and G.-X. Li, "A mathematical approach to establishing constitutive models for geomaterials," Journal of Applied Mathematics, vol. 2013, 2013.

[12] Q. B. Zhang and J. Zhao, "A review of dynamic experimental techniques and mechanical behaviour of rock materials," Rock Mechanics and Rock Engineering, vol. 47, no. 4, pp. 1411-1478, 2014.

[13] Q.-F. Gao, H. Dong, Z.-W. Deng, and Y.-Y. Ma, "Windinduced dynamic amplification effects on the shallow foundation of a horizontal-axis wind turbine," Computers and Geotechnics, vol. 88, pp. 9-17, 2017.

[14] C. Ma, D. Lu, X. Du, and A. Zhou, "Developing a 3D elastoplastic constitutive model for soils: a new approach based on characteristic stress," Computers and Geotechnics, vol. 86, pp. 129-140, 2017.

[15] L. Zeng, J. Ye, J. Zhang, J. Liu, and C. Jia, “A promising SPEEK/MCM composite membrane for highly efficient vanadium redox flow battery," Surface and Coatings Technology, vol. 358, pp. 167-172, 2019.

[16] J. M. Duncan and C.-Y. Chang., "Nonlinear analysis of stress and strain in soils," Journal of the Soil Mechanics and Foundations Division, vol. 96, no. 5, pp. 1629-1653, 1970.
[17] P. Jonsén, H.-Å. Häggblad, and G. Gustafsson, "Modelling the non-linear elastic behaviour and fracture of metal powder compacts," Powder Technology, vol. 284, pp. 496-503, 2015.

[18] J. C. Criscione and K. R. Rajagopal, "On the modeling of the non-linear response of soft elastic bodies," International Journal of Non-linear Mechanics, vol. 56, pp. 20-24, 2013.

[19] L. Domaschuk and P. Valliappan, "Nonlinear settlement analysis by finite element," Journal of Geotechnical and Geoenvironmental Engineering, vol. 101 ASCE\# 11423 Proceeding (1975).

[20] B. Lei, C. M. Fan, and M. Li, "The method of fundamental solutions for solving non-linear Berger equation of thin elastic plate," Engineering Analysis with Boundary Elements, vol. 90, pp. 100-106, 2018.

[21] J. Ge, C. He, J. Liang, Y. Chen, and D. Fang, "A coupled elastic-plastic damage model for the mechanical behavior of three-dimensional (3D) braided composites," Composites Science and Technology, vol. 157, pp. 86-98, 2018.

[22] A. H. Sofiyev, Z. Karaca, and Z. Zerin, "Non-linear vibration of composite orthotropic cylindrical shells on the non-linear elastic foundations within the shear deformation theory," Composite Structures, vol. 159, pp. 53-62, 2017.

[23] J. Zhang, "Rapid estimation of resilient modulus of subgrade soils using performance-related soil properties," International Journal of Pavement Engineering, pp. 1-8, 2019.

[24] E. E. Alonso, J. Vaunat, and A. Gens, "Modelling the mechanical behaviour of expansive clays," Engineering Geology, vol. 54, pp. 1-2, 1999. 